\title{
La tecno-ciencia en cuestión. Elementos para una arqueología del siglo XX*
}

\author{
Philippe Breton** \\ Alain-Marc Rieu ${ }^{\star \star}$ \\ Franck Tinland $^{* * *}$ \\ Traducción del francés al español \\ de Luis Alfonso Palau Castaño \\ Dol: 10.22395/csye.v6n11a13
}

\section{Introducción}

Técnicas avanzadas, tecnologías de punta, desafío técnico, transferencia de tecnología, riesgos tecnológicos importantes, tecnoestructuras, biotecnologías... La técnica o el envite del siglo ${ }^{1}$... Discursos y escritos nos devuelven el eco de los efectos inducidos por el desarrollo de los instrumentales a través de los cuales nuestras sociedades dominan y utilizan energía e información.

Estos efectos son de todos los órdenes; afectan, además de la producción directa de los resultados buscados por la propia operación técnica, los intercambios económicos, las relaciones de potencia entre los individuos, los grupos, las naciones, para no mencionar los continentes; las modalidades de la comunicación entre los hombres; la representación que se hacen del pasado como del porvenir, el rol del conocimiento y las finalidades de la investigación científica; los equilibrios ecológicos y el conjunto del medio terrestre.

La rapidez del desarrollo tecnológico, su peso creciente en el corazón de nuestra vida cotidiana, tanto como en la determinación de las estrategias a es-

\footnotetext{
Estos fragmentos corresponden al libro que tiene el mismo el nombre, publicado en Seyssel por la editorial Champ Vallon en 1990. Traducción del francés al español de Luis Alfonso Palau, Medellín, febrero d 2015-abril de 2017. Nota del editor.

** Antropólogo y sociólogo francés nacido en 1951, investigador en el CNRS (Laboratorio Culturas y sociedades en Europa, UMR 7043 del CNRS en Estrasburgo) y profesor en la Universidad de París I. Philippe Breton centra sus estudios sobre la antropología de la palabra y de la técnicas de comunicación. Nota del editor.

*** Specially Appointed Professor, Center for the Study of Co Design (CSCD), Osaka University. Professor emeritus, University Lyon, Jean Moulin. Senior Research Fellow, Trans-science project, IETT, University Lyon, Jean Moulin \& IAO, Ecole Normale Supérieure Lyonas. Nota del editor.

**** Profesor de filosofía en la Universidad de Montpellier. Autor entre otras de: La diferencia antropológica, 1977, y de Derecho natural, ley civil y soberanía en la época clásica, 1988. Co-autor de La tecnociencia en cuestión. Seyssel: Champ Vallon, 1990. Nota del traductor.

1 Jacques Ellul (1954). El siglo XX y la Técnica: Análisis de las conquistas y peligros de la Técnica de nuestro tiempo, Barcelona: Labor, 1960.
} 
cala planetaria, coge cortico, y a veces a contrario, maneras usuales de pensar y de actuar, códigos jurídicos, instituciones y autoridades establecidas.

Permanecemos divididos entre esperanzas e inquietudes frente a un progreso que, no solamente desplaza los límites de lo posible, sino que parece a veces abolirlos para dejar resurgir mejor, tras él, nuevos peligros ligados al uso de una potencia demiúrgica. La tentación es entonces o la de huir hacia delante, en un acto de fe que anticipe en el desarrollo de nuestros medios de acción el remedio a todas las dificultades del presente, o la de voltearse nostálgicamente hacia tiempos de armonías desaparecidas... y, por lo menos, hipotéticas.

La cuestión, sin embargo, no es ni creer en la omnipotencia de una técnica necesariamente bienhechora en virtud de las intenciones iniciales que la destinan al servicio de los hombres, ni de condenar lo que tendría que ver con la desmesura propia de una voluntad, si no demoníaca, al menos insensata. Se trata más bien de comprender el hecho mismo del desarrollo técnico, de reencontrar sus condiciones y orígenes, de despejar la dinámica subyacente a este proceso, de explicitar sus efectos en todos los órdenes, para no hablar de la circunscripción de sus límites. La técnica y todo lo que le está ligado constituyen, en efecto, una forma específica de realidad, que es necesario conocer por ella misma, antes de anticipar sus consecuencias, de evaluar sus oportunidades o sus riesgos, y, cuando sea pertinente, definir sus posibilidades u orientar su devenir.

La potencia de nuestra técnica, con su doble enraizamiento en el dominio de la energía como en el almacenamiento y tratamiento de la información, se sitúa en la prolongación de una historia bien antigua, e introduce al mismo tiempo mutaciones profundas en nuestras relaciones con la naturaleza tanto como con nuestros semejantes. Es por esto que conviene sopesar lo que es aquí herencia y lo que es novedad. Nos toca pues puntualizar con respecto al conjunto de las condiciones que han hecho posible nuestro presente, y con respecto a las virtualidades de las que este es portador con respecto a nuestro porvenir, próximo o lejano.

Ahora bien, nos faltan indicadores para apreciar con clarividencia nuestra situación, la que nos ofrecen nuestros "medios" técnicos.

Sin duda será preciso comenzar por persuadirnos de que lo que tiene que ver con la tecnicidad desborda con mucho lo que exhibe ante nuestros ojos el instrumental característico de nuestras sociedades. Herramientas, máquinas, talleres, computadores, televisores o teléfonos no son sino los puntos visibles de un tejido complejo, que entrecruza las múltiples relaciones que solidarizan a los unos con los otros, a objetos técnicos, hombres, instituciones, saberes y habilidades. 
Frente a esta realidad compleja, opaca en sus dimensiones subyacentes como en los efectos que ejerce sobre su contexto natural o social, nuestra herencia cultural nos deja relativamente desarmados. Durante mucho tiempo la pariente pobre en el seno de las actividades humanas, relegada lejos de los que constituía la nobleza de las ocupaciones calificadas de liberales puesto que estaban alejadas del trabajo sobre la materia y sus limitaciones, acantonada en la producción de lo útil, por definición subordinada a más altos valores, no ocupa un sitio importante en la historia de nuestro pensamiento. Apenas si es evocada con mucha frecuencia como aprovechamiento o apéndice de las actividades consagradas a la manifestación de lo verdadero, de lo bello y del bien, tales como la filosofía, la ciencia, el arte, la ética, la política. La poca consideración que se le tiene a la "enseñanza técnica", en comparación con las especialidades "clásicas" da fe de la permanencia de esta tradición en el corazón mismo de una época fascinada por sus "tecnologías"; es verdad que la manipulación de los símbolos y la construcción de programas tienen poco que ver con el carácter menesteroso del trabajo encarnizado por vencer la resistencia de los materiales, y por ahí mismo como contaminado por la materialidad de las cosas ${ }^{2}$.

Ciertamente numerosos estudios y obras se han publicado en las últimas décadas. La literatura sobre las técnicas o tecnologías se ha hecho profusa. Pero todavía tenemos que la realidad que recubre esos términos es de una complejidad inagotable. Muchos de sus aspectos son todavía insospechados. Otros, tan pronto se los percibe, dejan entrever prolongaciones y ramificaciones que les dan la fecundidad, pero también los límites, de sondeos, preludios a investigaciones más sistemáticas.

De todas las contribuciones posibles, sin embargo, no son demasiadas las dedicadas a la elucidación del fenómeno técnico, en sus características internas como en sus interferencias con el entorno natural y social, en su más grande

2 En el Timeo, Platón evoca la reencarnación de las almas en cuerpos que corresponden a los hábitos de vida. Por ejemplo, los hombres que no le han "prestado ninguna atención a la filosofía" y no han tenido "ojos para observar la naturaleza del cielo", son víctimas de los hábitos que los han inclinado hacia las cosas de abajo: "como consecuencia de esos hábitos, sus miembros anteriores y sus cabezas se han inclinado hacia la tierra, atraídos por la afinidad que sienten con ella. Su cráneo se alargó y tomó toda clase de formas (...) Por esta razón también esa clase de seres nació con cuatro patas o más, incluso. El Dios dio a los más estúpidos más puntos de apoyo, ya que ellos estaban más atraídos a la tierra" (Timeo, 91 e; Obras completas, Aguilar, p. 1178). Sin duda, más que al trabajo, esto concierne principalmente a los deseos y a la búsqueda de los placeres sensibles... Pero sólo una existencia desprendida de toda preocupación material puede elevarse a la contemplación de la verdad y de la naturaleza del Cielo. El rechazo de los trabajos que sujetan el alma a la "tierra" se reencuentra en la concepción platónica de las matemáticas y de su rol en la formación de las "élites"; es necesario que "los que deben encargarse de las más altas funciones públicas" se dediquen a las matemáticas de manera que "alcancen la contemplación de la naturaleza de los números sirviéndose de la inteligencia. Porque aquella no es de uso exclusivo de los comerciantes y chamarileros, ni se ciñe tan solo a las compras y a las ventas, sino que puede aplicarse a la guerra y a facilitar una vuelta del alma misma al mundo de la verdad y de la esencia" (República, 525 c; Obras completas, Aguilar, p. 785). Los que no posean cualidades necesarias para ellas, deben ser "relegados a los artesanos y labradores". 
generalidad como en las particularidades ligadas a la diversidad de los instrumentales y prácticas que en ellas operan.

La presente obra quiere poner de manifiesto, a través de la diferencia de las perspectivas adoptadas (e incluso sin mencionar las discordancias ligadas a los presupuestos propios de cada uno de los tres autores), la amplitud de las cuestiones que plantea la forma que ha tomado el desarrollo tecnológico contemporáneo.

Esta amplitud no es de orden puramente teórico. La reflexión sobre la técnica, las búsquedas sobre el mundo de las tecnologías conciernen modalidades de organización y dinámicas propias de la actividad técnica misma y de sus medios. Estas modalidades de organización y esas dinámicas internas al mundo de la técnica fabrican nuestras relaciones con el mundo, nuestras relaciones con nuestros semejantes, nuestra percepción del porvenir. Su elucidación implica la toma de conciencia de oportunidades y riesgos, de capacidades y de resistencias que abren sobre escogencias que se han vuelto esenciales para nuestro destino.

Por ejemplo, se requeriría explicitar ampliamente las mutaciones inducidas por el desarrollo de los "medios" técnicos sobre la manera de concebir la historia misma. Habría que confrontar a las grandes tentativas del siglo XIX para descifrar el sentido de la historia, la situación que se nos presenta dada la necesidad de pensar nuestro devenir frente a la posibilidad de un final brutal de la aventura humana, posibilidad virtualmente contenida en el abanico de los medios de destrucción masiva de que disponen nuestros contemporáneos, tanto como frente a la lenta alteración de los equilibrios que hacen de este planeta un lugar tan singular, frágil en su excepcionalidad, en el seno de un cosmos por todas partes además "aséptico". Tampoco deberíamos olvidar las perspectivas, que no podemos considerar insignificantes, evocadas por el título mismo de una reciente obra: el Cerebro planetario ${ }^{3}$.

Las perspectivas abiertas en las páginas siguientes son ciertamente más modestas de lo que lo deja pensar la evocación de este horizonte del que depende el sentido último de una aventura promovida desde los comienzos de la humanidad y, sin embargo, tan nueva en sus manifestaciones contemporáneas. Sin que un tal horizonte le sea completamente ajeno, las preguntas que acá abordamos son más limitadas, pero más precisas. Ellas buscan, en lo esencial, un efecto de retroceso, de distanciamiento que permita encontrar las verdaderas dimensiones, el espesor, la opacidad misma de fenómenos de los que estamos muy próximos, en los que estamos demasiado comprometidos como para percibir condiciones, modalidades y apuestas.

3 Joël de Rosnay. Le Cerveau planétaire. París: Olivier Orban, 1986. 
En suma, esta obra respondería a los propósitos de sus autores si pudiese sugerir pistas de investigaciones, abrir el campo de reflexiones más profundas sobre lo que es, sino la, al menos una de las características más importantes de nuestro tiempo.

Los textos que reúne presentan tantas facetas que ofrecen al lector "perfiles" diferentes de una misma realidad, a la vez específica y ligada a otras dimensiones de lo que constituye el "medio" en el que se desenvuelve nuestra vida.

Las partes y capítulos están ordenados siguiendo una trayectoria que conduce de los fundamentos históricos a partir de los que la cultura europea se constituyó en medio propicio al desarrollo científico y técnico, a un análisis de la forma específica tomada por ese desarrollo con la emergencia -luego la rápida expansión- de las tecnologías informáticas. En el intervalo que separa estos estudios sobre el momento fundador de la racionalidad tecno-científica, y las páginas consagradas al relevo que las tecnologías de la información toman prolongando las tecnologías energéticas en el papel de motor del cambio en la época contemporánea, es el conjunto del orden técnico el que es objeto de análisis buscando desprender sus características internas, evocadoras de autonomía, tanto como sus relaciones complejas con el pensamiento filosófico, con la cultura de nuestro tiempo, con los juegos de poder o los equilibrios naturales.

Esta presentación de fenómenos esenciales de nuestro tiempo comporta necesariamente lagunas. La obra cuya lectura proponemos no podría considerarse como un estudio exhaustivo de esta realidad multidimensional que nace de las actividades humanas, pero que desborda con mucho la conciencia que los hombres tienen de ella.

Pero, al menos, estas vistas perspectivas deben permitir ante todo que el lector se vuelva atento a la complejidad de los procesos de los que sacamos nuestro poder sobre las cosas, y por ahí, de las dificultades inevitablemente encontradas por toda política de desarrollo tecnológico. Ellas pueden luego -y tal es el deseo de sus autores- abrir debates y suscitar investigaciones a partir de lo que aquí a veces está más sugerido que demostrado.

Las diferencias de puntos de vista que salen a la luz a través de estas páginas -diferencias que los autores no han buscado borrar de ninguna manera- son de tal naturaleza que permiten conducir a una puesta en discusión de las certidumbres completamente hechas sobre las que reposan, muy frecuentemente, nuestras actitudes con respecto a lo que es (para lo mejor y para lo peor) el principio de las oportunidades y riesgos según los cuales se trama nuestro destino. Y si, habiendo cerrado este libro, el lector considerase con otros ojos los actos más cotidianos que él realiza, al utilizar su afeitadora eléctrica, su automóvil 
o su teléfono inteligente, y volviera a colocar sus gestos sobre el fondo de las condiciones de las que ellos sacan su eficacia y fines que les dan un sentido, los autores tendrían la satisfacción de haber tomado modesta parte, pero real, en una de las tareas más urgentes de nuestro tiempo: comprender lo que está en el principio de nuestra potencia, las inquietudes que de ello surgen y los imperativos que nos imponen.

Franck Tinland

\section{$* * *$ \\ Segunda Parte \\ La experiencia contemporánea del desarrollo científico y técnico (pp. 97-119)}

¿Cómo pensar el complejo tecno-científico en la actualidad? ¿Cómo conocerlo? La primera parte no tenía solamente por objetivo describir la evolución de las ciencias y de las técnicas del Renacimiento a la Revolución Industrial; ella quería proponer un análisis del punto de vista de su contexto social y cultural. No disponemos hoy de un saber que permita hacer frente a la mutación que trastorna nuestras sociedades. Se querría simplemente proponer dos enfoques complementarios.

El otro es desarrollado en esta segunda parte; consiste en formular la experiencia actual de la tecnología, recorrer los grandes temas que conciernen a los individuos que somos, así como también a la sociedad en la que vivimos. Es a partir de esta temática que el pensamiento puede intervenir sobre las orientaciones a largo plazo de los saberes, porque ella marca la toma de conciencia colectiva de que el destino de la humanidad tanto como nuestra vida cotidiana están en juego, que el desarrollo técnico exige una reflexión sobre sus finalidades, sobre decisiones que comprometen durablemente nuestras sociedades, y que, sin embargo, escapan al control de los individuos.

\section{La técnica como mediación y como sistema}

\section{Continuidad y mutación}

Luego de un tiempo muerto, la referencia a la "crisis" sustituyó el llamado "sentido de la historia", como indicadora de la manera como nuestros contemporáneos viven y reflexionan su relación con el curso de los acontecimientos, con sus certidumbres y con su porvenir. 
Pero si el sentido de la historia implicaba una apertura positiva a las dificultades del presente, la crisis nos deja ante el enigma de una situación a cuyo rebasamiento (a la vez necesario y deseable) no nos conduce ninguna dinámica interna. Hemos perdido la fe positivista o dialéctica en los motores de nuestro devenir.

Muchas razones podrían ser invocadas para explicar un tal cambio. Habría que indicar los desplazamientos de fronteras que, con respecto a la primera mitad del siglo y, a fortiori, con respecto al siglo XIX (cuya herencia gobierna aún nuestros pensamientos) han abierto nuevos frentes, han hecho surgir apuestas de rivalidades antaño desconocidas, han proyectado actores hasta entonces marginales al proscenio del escenario mundial.

Pues resulta que estos cambios, que afectan los ejes y las oposiciones en función de lo que se ordena como representación que las sociedades tienen de su devenir, la impresión de mutaciones difícilmente controlables, complejas, se integran una buena parte de forma aleatoria y, en todo caso, imprevisibles. Sin duda, es entonces cómodo y, en un sentido, tranquilizador, buscar puntualizar con respecto a lo que se deja aprehender más fácilmente por el juego de las comparaciones cifradas, y de referirse a los indicadores económicos. Ellos permiten establecer, de manera más o menos precisa, "diagnósticos" al analizar las perturbaciones de los equilibrios en la producción o los intercambios, y de intentar pronósticos relativos a la restitución de mecanismos reguladores que aseguren, ya sea el retorno al estado que precedía el desarreglo actual, ya se el advenimiento de un nuevo orden.

Cuando sobreviene la sospecha de una insuficiencia en la determinación de esta crisis a partir de la perturbación de los juegos económicos, es a una conmoción de los valores culturales y a un "temblor de civilización" a los que uno se refiere, constatando entonces la borradura de bastantes evidencias, la obsolescencia de modos de vida, el desmoronamiento del consenso tradicional, la generalización del sentimiento de que "esto no puede durar mucho tiempo así como está". Pero los discursos sobre esos temas siguen siendo vagos, y sin conexión con la novedad de una situación descrita por entonces en términos esencialmente negativos.

No se trata de negar la importancia de las determinaciones económicas y de sus limitaciones internas específicas. Tampoco se trata de descuidar las profundas mutaciones que han afectado la consciencia que nuestros contemporáneos tienen de ellos mismos y de lo que los rodea.

Por lo demás, es seguro que lo que llamamos "crisis" no es reductible a los efectos de ninguna de las series que concurren a hacer de una sociedad lo que ella es. 
Entre los factores constitutivos de la situación nuestra, se puede, sin embargo, avanzar la hipótesis (sin ser demasiado aventurero) según la cual la serie tecnológica ocupa un lugar de primer orden. Los cambios que en ella se operan inducen claramente transformaciones indirectas. Los polos de riqueza o de penuria se desplazan en la medida de las posibilidades y de las necesidades técnicas inherentes a la explotación de los recursos naturales y humanos. Múltiples lazos de dominación y de subordinación se tejen, y a veces se deshacen, a través de las transferencias de aparatajes y de competencias. Las relaciones de dependencia económica y de fuerzas estratégicas se modifican en función de las capacidades tecnológicas.

En efecto, la técnica no se limita a proveer los medios de una acción eficaz sobre las cosas. Su "mundo" está muy lejos de reducirse al conjunto de las herramientas y máquinas disponibles para actuar sobre las "cosas" y explotar los recursos utilizables. La técnica estructura también las relaciones entre los hombres, asignándoles funciones y posiciones en el marco de las posibilidades que ella abre. Ella transforma las posibilidades de transmisión de las habilidades, redistribuye los papeles tanto desde el punto de vista geográfico como jerárquico, engendra relaciones de dependencia que son el principio de la capacidad para los unos de actuar sobre los otros, ya sea directamente, ya sea por mediación de una transformación de sus condiciones de vida. Sugiere y estructura finalmente las representaciones que los hombres tienen de sí mismos, del mundo y de lo que pueden desear.

Sin duda, no conviene aislar la esfera tecnológica del conjunto de las determinaciones propias de un conjunto socio-cultural más o menos sistemático. Pero si la estructuración y el desarrollo del subconjunto "técnico" dependen evidentemente de factores económicos, de hábitos tradicionales o de decisiones políticas, esta dependencia, por una parte, está lejos de ser unilateral, y por la otra, no es incompatible con una amplia parte de autonomía ligada a las regulaciones y limitantes internas que solidarizan los "medios técnicos" que funcionan para una sociedad en un momento definido de su historia y solicitan su evolución.

Existe unanimidad en considerar que la serie tecnológica ocupa un lugar singular entre todas aquellas en las que se puede analizar el funcionamiento y el devenir de las sociedades humanas. Manifiesta un carácter de continuidad y de progresividad que es difícil encontrar en otras partes sin correr un riesgo de arbitrariedad. También, tratar de establecer los componentes de lo que llamamos "crisis" es, desde que se reconozca la importancia de los factores tecnológicos, situar, a la vez, su rol sobre el fondo de lo que caracteriza a la técnica desde sus más antiguas manifestaciones, y señalar la novedad irreductible que marca nuestra época. 
Es pues, o debería ser, examinar en qué el presente es el remate de un lejanísimo pasado y, al mismo tiempo, ver en qué esta continuidad no es exclusiva de mutaciones profundas. En efecto, es posible que el desarrollo tecnológico pueda revelar simultáneamente lo que ya estaba virtualmente contenido en las formas rudimentarias de la industria humana, y una potencia de ruptura que coloca a los hombres ante problemas radicalmente nuevos, ya se trate de sus relaciones mutuas o de sus relaciones con la naturaleza.

Haremos pues nuestra la hipótesis según la cual puede ser aclarador, en el marco de una reflexión sobre lo que llamamos crisis, tener en cuenta la técnica bajo sus dos aspectos: el de la continuidad de su devenir, y el de la novedad de sus formas recientes.

Es en esta hipótesis que podemos plantear algunos jalones que permitan situar mejor nuestro momento, y de comprender mejor su especificidad. Se trata entonces de partir de lo que está más lejano, pero que, siendo aún actual, es también lo más común... para llegar hasta lo que caracteriza nuestra "edad" y se encuentra en el corazón de nuestra particularidad.

En efecto requerimos tomar en serio el hecho de que el poderío que nos ofrece hoy nuestra tecnología viene de lejos, de muy lejos. Tiene tras de sí una historia mucho más antigua que la historia. Y a este respecto, tiene que ver con una característica antropológica fundamental, y la revela.

Esta historia comienza hace más de tres millones de años. Las primeras herramientas son contemporáneas, o más o menos, de los primeros vivientes de silueta humana, es decir, caracterizados por un modo de locomoción y de prensión que reposa en una diferenciación, única en los primates, de las estructuras y funciones propias de las terminaciones de los miembros anteriores y posteriores, todo ello asociado a una postura vertical ecológicamente conectada a un hábitat terrestre (y no arborícola). Las primeras manifestaciones de la tecnicidad humana son solidarias de la manera como, a través de las posibilidades y limitaciones de un cuerpo así organizado, los hominianos se insertaron en el mundo, confrontados a la realidad física de su entorno natural. O dicho de otra forma: los objetos técnicos están ligados desde su aparición a la manera como los representantes del género homo, mucho antes de nuestra especie, pueden y deben conectarse con las cosas para apropiarse -hacerlas propias a las necesidades de su existencia- lo necesario a sus vidas.

Se ha dicho y se ha repetido que la herramienta prolonga la organización biológica. Se inscribe en línea recta con la multiplicación y la diversificación de los medios con los cuales los organismos se han encontrado dotados en el curso de la evolución para explotar su medio. Darwin introdujo esta perspectiva que luego fue alabada por Marx. 
De los pseudópodos de la amiba a las excavadoras de nuestras canteras, pasando por la pinza del cangrejo y la pata cavadora del topo, hay una especie de continuidad. La búsqueda de una eficacia siempre más grande en la apropiación de las cosas, es decir, también en su detección y su transformación, encuentra su impulso en las exigencias de la vida, en el modo de existencia propio a esos sistemas organizados auto-conservadores que son los vivientes. De esta manera la tecnicidad humana se enraíza (más allá de todas las diferencias concernientes a la génesis y a los mecanismos de aparición, de conservación, de transformación de las formas orgánicas y técnicas) en el orden biológico. Se enraíza mucho más allá de lo que dejan pensar los enfoques de la herramienta efectuados siguiendo las perspectivas psicológicas centradas en la inteligencia práctica y las conductas de invención. Estas aproximaciones no tienen casi ninguna pertinencia para pensar el origen y la naturaleza de la tecnicidad humana, puesto que la conexión directa con la morfología y los ritmos propios del conjunto del cuerpo se articula sobre la herencia tradicional y la memoria de grupo, de manera que fundamenta sobre la repetición y conservación, mucho más que sobre la innovación, la producción y la puesta en operación del utillaje.

Esta continuidad con respecto al orden biológico y a sus exigencias está, sin embargo, asociada a una profunda ruptura. Más precisamente, ella se acompaña de una ruptura que, radical desde sus orígenes, no manifiesta plenamente su sentido sino en el curso de una deriva de muchos millones de años. Durante muchísimo tiempo, esta ruptura permanece imperceptible y, sin embargo, eficiente. El tener en cuenta una escala de tiempo compatible con estas consideraciones es, a pesar de las apariencias, importante para comprender nuestra propia situación; esta no nació de un brusco accidente histórico o de una súbita mutación de genio humano. Y es más bien del lado del "modo de existencia de los objetos técnicos", que de un punto de vista exterior al desarrollo del universo técnico, que es preciso situarse para comprender nuestro propio momento, y su dinámica propia.

Es necesario indicar los caracteres fundamentales de la tecnicidad humana, los que distinguen desde los comienzos la herramienta de los instrumentos inorgánicos ocasionales utilizados por animales pertenecientes a especies alejadas las unas de las otras. Tales usos son más difundidos de lo que se pensaba antes. Pero ellos tienen solamente una relación lejana con las características propias de la tecnicidad humana, las que no se pueden aclarar-como ya se dijo-para nada por consideraciones sacadas de la psicología de la inteligencia. Para comprender la singularidad de la tecnicidad humana, conviene insistir sobre las relaciones transversales que conectan las herramientas entre ellas, mucho más que sobre 
la relación que une la herramienta a su inventor o utilizador. Habría que comprender la herramienta a partir del utillaje que hace posible su fabricación, su utilización, y, si es el caso, su invención. Este principio metodológico conduce, en un primer momento, a poner entre paréntesis a los hombres, inventores o artesanos, para aislar en una especie de pureza abstracta, pero reveladora, lo que hay de esencial en la mediación técnica, y lo que la distingue de toda otra forma de realidad o de actividad, ya se trate del uso de instrumentos en el animal, o de teorizaciones científicas en pleno siglo XX. Por supuesto, esta abstracción metodológica no es sino un momento en el proceso que conduce a una inteligencia global de la técnica. Pero conviene regresar sobre las "marcas" específicas de ella.

Entre estas características vamos a retener dos, ellas mismas en la base de una tercera. Ante todo, incluso bajo sus formas más arcaicas, el utillaje se presta a una clasificación tipológica, al punto que es a partir de criterios estadísticos que presuponen la existencia de tipos, que es posible distinguir las producciones del arte humano de las formas accidentalmente producidas por factores naturales. La conformidad con un tipo arranca a la herramienta de la particularidad de las condiciones a las que él estaría ajustado, y lo refiere a procesos de formación y de conservación mucho más profundos que eso que se puede entender bajo el término invención o innovación. Lejos de que esta última sea la característica de la tecnicidad humana, toda herramienta implica mecanismo de repetición, de reproducción, de conformidad con los estereotipos que durante centenares de millones de años han reducido a casi nada la parte del cambio que podría ser atribuida a conductas de innovación.

Estas consideraciones vienen a ser completadas por el segundo carácter de la tecnicidad: los tipos de herramientas se encadenan siguiendo series de las que se puede seguir su evolución durante muy largos períodos y que evocan la idea de "linajes" que se desarrollan, diferenciándose, según ejes cuasi ortogenéticos. Se puede así seguir durante centenares de miles de años la evolución del biface al paleolítico inferior, siguiendo una búsqueda de simetría, de regularidad, de miniaturización, de mejor relación entre la cantidad de material utilizado y la parte de filo utilizable que permite definir el sentido de un progreso interno, a la vez, lento y continuo. Esta progresión ella misma se inscribe en la historia nunca acabada de los objetos cortantes, notable en su continuidad desde las industrias líticas hasta nuestros días. Así, las innovaciones se inscriben en una especie de dibujo de conjunto que impone la idea de una evolución que obedece a sus leyes propias, "autó-noma", que canaliza las innovaciones bruscas. Esto tiene por consecuencia que en un primer sentido toda herramienta nace de una herramienta, de un utillaje portador de posibilidades y de limitantes que le son propios. 
Los tipos mismos evolucionan siguiendo líneas directrices profundamente hundidas en el espesor del tiempo. Este "progreso" testimonia una continuidad que en términos diferentes, y en materiales diferentes que, aun cuando remiten a edades tecnológicas bien alejadas las unas de las otras, han sido sacadas a flote por A. Leroi-Gourhan y G. Simondon ${ }^{4}$. El devenir de las herramientas o máquinas obedece así a principios internos, sigue sus propias leyes, mientras que todo el tiempo permanece sostenido por esa búsqueda de la eficacia sin la que nos deslizaríamos hacia la preponderancia de las funciones rituales y estéticas. Las regulaciones internas de la actividad técnica juegan en profundidad, y sobre períodos a veces larguísimos ${ }^{5}$ un rol sin medida común con los aportes conscientes de los hombres.

$\mathrm{El}$ artesano o el ingeniero son ante todo herederos. En la diversidad de sus actitudes, son en segundo lugar, los instrumentos de actualización de los posibles, abiertos por la herencia tecnológica. Sus obras se inscriben en la confrontación que se realiza entre la búsqueda de la eficacia (movida por deseos ellos mismos informados por el aparataje técnico disponible y sus actuaciones) y la realidad de un mundo que, en función de ese utillaje, revela conexiones y resistencias. El objeto técnico tiende así a desarrollarse según una dinámica que le es propia, incluso si ella toma prestados los medios del deseo y del trabajo humano. Esta dinámica reposa sobre interacciones y circuitos de información que escapan a las estrictas limitantes que presiden la conservación de las formas específicas y de los equilibrios ecológicos en el orden de la vida. Por lentos que hayan podido ser los primeros desarrollos tecnológicos, y por irregulares que sean los ritmos de ese progreso, ellos introducen modalidades de transformación y de ritmo de devenir en ruptura con las características de la evolución biológica. La prosecución del contacto eficaz por la mediación de estructuras inorgánicas se traduce por la emancipación de la esfera tecnológica y su autonomización, a la vez, con respecto a las regulaciones que controlan la evolución de los vivientes, y con respecto a las intenciones o proyectos en función de los cuales los hombres tienen conciencia de actuar.

4 A. Leroi-Gourhan (1945). El gesto y la palabra. Caracas: Universidad Central de Venezuela, 1971. G. Simondon (1958). Sobre el modo de existencia de los objetos técnicos. Buenos Aires: Prometeo, 2007.

5 Habría que situar aquí los procesos (descritos por G. Simondon) de desarrollo y de integración funcional de los dispositivos de enfriamiento en los motores de combustión interna, o la complejización de la estructura filamento-rejilla-placa en las lámparas "radio" sobre el fondo de la continuidad impuesta por el estudio de los más antiguos testigos de la industria humana. Por ejemplo: "Homo sapiens perfeccionó las técnicas, diversificó las formas, desarrolló la industria ósea nacida al tiempo de los australopitecos, creó el arte mobiliario y arte parietal; pero mientras tanto permaneció, en lo concerniente a la industria lítica, en el linaje muchas centenas de veces milenario de sus predecesores (...) Hay que tener en cuenta el punto de vista del prehistoriador. Él no constata ninguna discontinuidad (...) durante más de 3, 5 millones de años". L. Balout. La préhistoire, origine et évolution des outils de pierre. Origines de l'homme. París: Museo del hombre, 1976, pp. 49 ss. 
Pero estos caracteres aparecen más claramente si se piensa en otro aspecto bajo el cual la herramienta, primero nacida lo más cerca de las funciones biológicas y siempre ligada a las exigencias de la vida orgánica, escapa al orden de la vida para constituir, al término de una larga deriva, el elemento visible de un "mundo" sometido a sus propias leyes de organización y de desarrollo, capaz igualmente de remodelar necesidades y deseos.

En efecto, las herramientas no son sino testigos, discontinuos y separados, de un conjunto que condiciona su existencia y determina su operatividad. Ningún objeto técnico es concebible por fuera de su participación en un entorno específico, en un "medio técnico" según los términos de A. Leroi-Gourhan. Ese medio desborda muy ampliamente la colección de los elementos constitutivos de aparataje disponible en una sociedad. No podría ser reducido a una yuxtaposición pasiva de los diversos objetos o prácticas en relación con las actividades técnicas.

En el sentido fuerte del término, este medio forma sistema o, al menos, tiende a organizarse como sistema. A pesar de la distancia que separa al objeto material que está conectado con las cosas, de los signos que usa la palabra, no es ya legítimo describir el equipamiento técnico de una sociedad enumerando las herramientas y máquinas de las que dispone, como no lo es el reducir una lengua a la nomenclatura de las palabras que ella comprende.

Todo objeto técnico es, en su fabricación y en su uso, solidario en derecho de los otros objetos fabricados y de los materiales sobre los que reposan las potencialidades de acción eficaz sobre las cosas en un territorio y en unos momentos dados. Además, el aparataje, los procedimientos de fabricación o de puesta en funcionamiento, las modalidades de transmisión de las habilidades, las representaciones sobre las que se guían las prácticas técnicas forman un conjunto solidario, ligado por múltiples interacciones, sin que esta sistematicidad sea un obstáculo para las relaciones que este conjunto mantiene con los otros aspectos de la misma cultura. Los ejemplos de transferencia tecnológica, a cualquier nivel que operen, testimonian la imposibilidad de aislar el uso de una herramienta o de un material de su contexto y, recíprocamente, de la perturbación de dicho contexto por la introducción de objetos o de recetas alógenas ${ }^{6}$.

$6 \quad$ Nos podríamos referir aquí tanto al célebre ejemplo de los esquimales que integran los primeros cortafríos recibidos de sus visitantes en su propio sistema tecnológico (donde la disociación lámina percutor era ignorada), y le pusieron mango a esas láminas cosa que reprodujera el esquema de una azuela; o al de los pigmeos que recibieron hachas metálicas, con ocasión de intercambios con poblaciones periféricas; las percibieron como objetos que conferían prestigio y autoridad a sus detentadores, y no como herramientas más adecuadas para trabajar la madera; esto produjo profundos trastornos en la estructura (muy igualitaria) de su sociedad, y la aparición de "big men", figuras sociales hasta entonces desconocidas de la organización tradicional. 
Las cadenas operatorias en las que un procedimiento toma lugar, las aptitudes y hábitos propios al medio de acogida determinan las modalidades de uso y la significación práctica del objeto recibido. Este, a su vez, puede inducir una serie de efectos al propagarse progresivamente mucho más allá de las modificaciones en las competencias técnicas.

Independientemente de estos hechos, el medio técnico en sí mismo funciona como un conjunto complejo y solidario de objetos, de competencias, de representaciones, que aseguran la mediación entre la manera como una sociedad percibe las necesidades cuya existencia reconoce, y el mundo natural que revela sus recursos en función de las habilidades y de los proyectos correlativos de los medios de acción disponibles. Esta mediación no es para nada inerte. Sometida, con más o menos vivacidad según las culturas, a las normas salidas de la búsqueda del contacto eficaz, ella tiende al desarrollo de una dominación creciente de las herramientas y procedimientos sobre el mundo, por medio del juego de las interacciones internas y de regulación de efecto realimentación positiva. Este desarrollo implica no solamente el mejor ajuste de los medios técnicos existentes a un mundo inmutable, sino también la apertura de un horizonte de posibles radicalmente nuevos en la revelación correlativa de modalidades insospechadas del poder de intervención sobre las cosas, y de un mundo en el que se perfilan "recursos", "materiales", "energías", utilizables pero hasta entonces desapercibidos. Hay una "génesis recíproca"7 de la influencia ejercida por la mediación de las herramientas y de las conexiones ofrecidas por el mundo, como hay una "dialéctica del arma y de la coraza", que encadenan en un desarrollo auto-mantenido una cascada de relaciones entre lo que aparece, a veces, como causa, y a veces, como efecto.

Que se trate pues de la evolución de un tipo técnico, a través de las formas sucesivas de un mismo "linaje" de herramientas ${ }^{8}$, o de las relaciones que solidarizan objetos materiales, recetas, normas de fabricación o de uso, conciencia de necesidades, etc., la esfera técnica es por todas partes portadora de presiones evolutivas y de regulaciones internas que le confieren una amplia autonomía. Ciertamente que esta no significa para nada independencia. Estas tendencias

$7 \quad$ Término tomado de Maurice Pradines (1948). Tratado de psicología general. t. I: el Psiquismo elemental. Buenos Aires: Kapelusz, 1962... y con el cual él designa los efectos mutuos que ejercen dos series de fenómenos que evolucionan de manera correlativa dentro de un mismo conjunto funcional, de suerte que "lo que es ulterior modifica la constitución de lo que es anterior", fijando así una "apariencia de consecución y de derivación engañosa", allí donde hay co-desarrollo sincrónico.

$8 \quad$ Cfr. A. Leroi-Gourhan (1943): "parece que todo sucede como si un prototipo ideal de pez o de sílex labrado se desarrollase siguiendo líneas preconcebidas: en el primer caso, del pez al anfibio, al reptil, al mamífero o al pájaro; en el segundo, de una masa amorfa de sílex, a las láminas retocadas esmeradamente, al cuchillo de cobre o al sable de acero", de suerte que el desarrollo de los tipos técnicos "imita" la deriva filética... Evolución y Técnica I: el Hombre y la Materia. Madrid: Taurus, 1988, p. 13. 
a la auto-organización y al auto-desarrollo entran en composición con las otras dimensiones de regulación socio-cultural. Ellas pueden ser neutralizadas o favorecidas por el lugar que se le hace a la dominación sobre las cosas en el seno de una cultura. Pero la tendencia a una autonomía sistemática anima desde sus comienzos (como anima, sin nunca lograr su completa realización, las otras dimensiones de la producción por parte de los hombres de estructuras a la vez ancladas en... y exteriorizadas con respecto al orden de la vida) al conjunto de las mediaciones por las cuales las sociedades humanas han emprendido la explotación de su entorno y sacar de él los recursos necesarios para la sobrevivencia de los individuos como para el funcionamiento de los circuitos de intercambios que aseguren su cohesión regulada. La esfera técnica tiende sordamente (pero de manera continua) a una triple emancipación: 1/ con respecto al orden biológico en el que ella encuentra su anclaje, 2/ con respecto a la conciencia que tienen los productores de su actividad y a las finalidades a las que ellos la piensan sometida, 3/ con respecto a las vicisitudes históricas, si es verdad que uno puede seguir el aumento de potencia de la tecnología a través de un devenir en matorral, desde el paleolítico hasta nuestros días.

De este modo, lejos de que el artesano o el ingeniero dominen lo que aparecería como su obra, ellos operan en el marco de las limitaciones y solicitaciones por las que ellos están consagrados a realizar lo que el equipamiento técnico hace posible a partir de una herencia. Esta herencia los conecta sin solución de continuidad con los comienzos de la industria hominiana, es decir, con muchos millones de años. Realizan así sus potencialidades, como envueltas en esa exteriorización y autonomización de las formas inducidas por la investigación de una conexión eficaz con las cosas.

La expansión técnica - diversificación de los objetos y de los procedimientos, movilización de fuerzas y búsqueda de potencia, rebasamiento de los límites de intervención sobre los materiales, etc.- es inherente al uso mismo de formas artificiales que mediatizan las relaciones del equipamiento orgánico humano y del mundo. Sin embargo, ha sufrido alternancias de aceleración y de estancamiento, y ha revestido -en medio de las otras dimensiones de la existencia social- una importancia variable. Condiciones sobre las que sería demasiado largo insistir han provocado una verdadera liberación de esta expansión a partir del comienzo de los tiempos modernos. Esta liberación marcó con sus propios caracteres, y con su potencia, a nuestra civilización. Ella ha conducido más recientemente a lo que era autonomía relativa a volverse hegemonía, pues las regulaciones propias del universo tecnológico extendieron su dominación sobre la mayor parte de las prácticas humanas. Al término de este proceso se perfila lo que J. Ellul describió (y denunció) bajo el nombre de "sistema técnico"9.

$9 \quad$ J. Ellul (1977). La edad de la técnica. Madrid: Octaedro, 2003. 
Conviene pues, ante todo, subrayar esta continuidad, no excluyente de mutaciones, por la que nos encontramos siendo herederos de lo que es estrechamente solidario de una característica antropológica fundamental, y de lo que al mismo tiempo se desarrolló, en relaciones ciertas con las circunstancias y los contextos históricos, en virtud de una dinámica propia del conjunto de los artefactos técnicos. Estos instituyeron un mundo mediador entre deseos y gestos humanos por una parte, y realidad física, por la otra. No podemos comprender la situación que es la nuestra sin insistir sobre esta continuidad y sobre esta autonomía de la mediación tecnológica, lo que no excluye que su desarrollo sea generador de situaciones radicalmente nuevas y, en particular, no está directa o indirectamente en el principio de la "crisis".

Si así son las cosas, se ve hasta qué punto son de poco peso las palabras y todas las tentativas por neutralizar -exorcizar- aquello cuya proveniencia es tan lejana, al mismo tiempo que esencialmente ligado a nuestro ser propio. Esta anotación no implica, evidentemente, la renuncia a asegurar la regulación de un mundo y de una dinámica de la que es necesario, ante todo, reconocer la realidad específica. Este mundo de los objetos y actividades técnicas es también opaco a la consciencia inmediata y también resistente al deseo humano como el mundo natural, cuyo "dominio" relativo presupone el conocimiento.

Pero importa también ver cómo, sobre el fondo de continuidad que acabamos de indicar, las técnicas contemporáneas introducen una radical novedad.

Esta novedad no podemos buscarla solamente en el éxito obtenido por el esfuerzo hacia más poder o hacia el rebasamiento de los límites encontrados hasta entonces por la dominación sobre las cosas, en función de su carácter "masivo" o, al contrario, "sutil", en función de su coherencia interna, de su solidez o, al contrario, de su dispersión, de su difusión. No podemos buscarla en la prosecución de niveles energéticos siempre más elevados. Todo esto se sitúa en la prolongación de los esfuerzos multi-milenarios para hacer más eficaz la energía muscular, para domeñar las energías que circulan "libremente" en la naturaleza (los flujos de aire o de agua), para liberar la energía "encerrada" en las estructuras materiales estables (madera, carbón, petróleo, átomo).

Requerimos, sin duda, buscar esta novedad principalmente del lado de los hechos de organización interna, y más particularmente por el lado de dos aspectos correlacionados de la realidad tecnológica: la reticulación del aparataje, y el reequilibrio de la relación entre las técnicas de dominio de la energía y las técnicas de memorización y utilización de la información.

$\mathrm{El}$ primero de estos puntos concierne a la aparición de objetos técnicos cuya dimensión y estructura son de una gran originalidad con respecto a lo que 
precedían. Se trata de las redes complejas que tejen un enmallado a veces muy apretado, coextensivo de los territorios que exceden, eventualmente, el de los Estados. Este enmallado va a la par con una diferenciación interna que permite el señalamiento de centros privilegiados, de nodos, de mecanismos reguladores y de efectores especializados conectados entre ellos por lazos funcionales sin solución de continuidad.

Estas redes aseguran no solamente la distribución de la energía y de la información, sino también su utilización por un aparataje muy diversificado que no podría ser desenlazado. La red E. D. F., por ejemplo, es un enorme objeto físico que, al mismo tiempo que está conectado con las redes vecinas, recubre el territorio nacional con una malla extraordinariamente densa, que penetra la cuasi totalidad de los lugares de trabajo y de habitación, que impone su mediación no solamente cuando se trata de mover las máquinas, sino también en la mayor parte de las ocurrencias de la vida cotidiana, cuando un individuo quiere usar su afeitadora, moler su café o subir al décimo piso de su edificio.

Para tomar consciencia de la omnipresencia, de la omnifuncionalidad de una tal red, habrá que encarar las repercusiones de un repentino fuera de servicio de ese mediador universal, tal como puede resultar de un acontecimiento (incidente técnico o acto deliberado) análogo al apagón del 19 de diciembre de 1978, momento en el cual interrupciones en cascada paralizaron en algunos minutos la mayor parte de las actividades en Francia, lo que engendró consecuencias a veces dramáticas.

El ejemplo de la red eléctrica es particularmente significativo. Pero también sería posible evocar la red telefónica (con una malla planetaria) o el conjunto de las infraestructuras desarrolladas en simbiosis con el automóvil (y que hace posible su desarrollo): carreteras, distribución de carburantes, sistemas de señalización, etc.

A las unidades técnicas separadas en las que pensamos espontáneamente ante un martillo, una prensa de embutir o una fábrica, se superpone este universo reticulado que, al margen de su funcionamiento y de sus exigencias propiamente técnicas y de los fenómenos de regulación que él engendra, desarrolla todo un conjunto de relaciones entre los hombres, suscita la institución de instancias de control, impone decisiones, hace surgir amenazas, tiende a imponer las normas y medios de su expansión, para no mencionar las necesidades que corresponde a sus capacidades.

La novedad principal es pues aquí aquella de una estructura que conduce a cubrir el hábitat humano con un sistema reticulado a la vez indispensable al orden habitual de la existencia social y frágil. 
La segunda novedad consiste no ciertamente en el nacimiento de las técnicas de almacenamiento y de tratamiento de la información, sino en un reequilibrado de su importancia con respecto a las que han acrecentado nuestra influencia física sobre las cosas, y que permite el control de la energía en sus diversas formas. Estas últimas resultan de la expansión de un sistema situado inicialmente en la prolongación de la fuerza muscular. Las primeras traducen más bien la exteriorización y la atonomización de artefactos que prolongan y retransmiten las funciones específicas del aparato nervioso.

Ellas no son nuevas; fFormas del grafismo, anteriores a la disociación de la escritura y de las figuras estéticas en la imprenta, luego a los dispositivos mecánicos que se encargan de los cálculos aritméticos, y está la larga historia de los procedimientos destinados a asegurar una memorización de la información y un apoyo a su utilización en el marco de diversas operaciones. Sería incluso interesante insistir sobre este extraño "acoplamiento" de un funcionamiento cerebral (por tanto orgánico) sin predeterminación genética stricto sensu, y de la inscripción sobre soporte inerte que caracteriza el sistema "lectura-escritura".

Sin embargo, es solamente en fecha reciente cuando la transferencia de funciones, que conducen a crear una tecnología autónoma para hacerse cargo del almacenamiento, el llamado y la combinatoria de la información, ha tomado un impulso de tal naturaleza, capaz de llevar esta tecnología al mismo nivel de aquellas que manipulan cosas sobre el fondo de utilización de la energía. Desde este punto de vista, el paso por la teoría de la información, la cibernética y la teoría de los sistemas sería, sin duda, la vía más adecuada para tomar la medida de la novedad que es la de nuestro propio "medio técnico".

Pero más importante aún es la relatividad de esta dicotomía entre artefactos que avasallan la energía a las necesidades de una conexión eficaz sobre los materiales, y artefactos relativos a la información, en la medida en que el enlace de los dos conjuntos permite la constitución de los autómatas que realizan (hasta en las grandes redes que acaban de ser evocadas aquí) esta unidad funcional que Grey Walter apercibía ya en 1951, cuando escribía: "hasta una fecha bien reciente, el universo de las máquinas estaba poblado de receptores y de efectores que rara vez estaban conectados entre sí, como si un universo estuviera lleno de nervios, de músculos, de glándulas, de ojos, de orejas, etc., aisladas, sin ninguna huella de médula espinal, ni, con mayor razón, de cerebro. El feed-back no es otra cosa que lo que se produce cuando un receptor y un efector están conectados entre ellos de tal suerte que el receptor pueda a la vez estimular al efector y ser estimulado por él. Es muy posible construir una máquina que manifestaría un comportamiento tan intencional como el de un insecto o de un vertebrado inferior" 10 .

10 W. Grey Walter. "Aspectos de la electro-fisiología de los mecanismos mentales" in Perspectivas cibernéticas en psico-fisiología. p. 16. 
Así se encuentra reforzado el aspecto sistemático de un medio técnico cuya organización interna y autonomía funcional imponen sus limitaciones propias a los hombres que utilizan tal mediación en casi todas las situaciones en que tienen relación con el mundo. O dicho de otro modo: este mediador universal, simultáneamente multiplicador de posibilidades y de obligaciones, se desarrolla siguiendo una lógica interna que produce efectos secundarios sobre el mundo social (al reestructurar los lazos de dependencia mutua y al hacer surgir nuevas situaciones de poderes, por tanto conflictos nuevos) y sobre el mundo natural. Esos efectos, al margen de los resultados obtenidos en línea recta de las intenciones técnicas que buscan la transformación del dato por medio de una actividad subordinada a la satisfacción de las necesidades o deseos están, por una parte, en la base de lo que se vive como crisis.

Desde comienzos de los años 1970, límites y riesgos ligados a esta hegemonía técnica se han perfilado en el horizonte de nuestros proyectos. La prolongación de la curva representativa de la expansión del sistema precedentemente descrito y la perpetuación de las esperanzas que le estaban ligadas parecen menos seguras en nuestros días que hace algunas décadas. Lo que llamamos crisis está también ligado a esa incertidumbre, y a sus razones.

$$
* * *
$$

En 1989, puede parecer de mal gusto recordar el primer reporte publicado por el Club de Roma bajo el título "Alto al crecimiento". Si algo se detuvo, fue algo que se hizo de forma poco voluntaria y poco apreciada. Ese título como las conclusiones del reporte merece, sin embargo, aún algunas reflexiones, desprendidas del contexto pasional que las acompañaba en aquella época.

Más allá de las evaluaciones y de los modelos formales demasiado fácilmente expuestos al desmentido de los hechos, lo esencial residía en la idea fuertemente simple según la cual un sistema en expansión acelerada no puede indefinidamente desarrollarse en una envoltura finita. En la vecindad de los límites inherentes a las posibilidades del entorno terrestre debían producirse desequilibrios y generalizarse desórdenes capaces de desarticular una civilización que se ha vuelto planetaria. Las evaluaciones iniciales del Club de Roma sub-estimaban, ciertamente, los recursos del "navío espacial Tierra", tanto como la flexibilidad adaptativa de las sociedades contemporáneas. Pero nada nos asegura que en la más larga duración, las anotaciones y las advertencias hechas entonces estén desprovistas de significación.

Más allá de las diversas manifestaciones algunas veces pintorescas o ingenuas, nos hemos vuelto más sensibles a las lecciones dadas desde Haeckel por la ecología. Esta reposa sobre la idea según la cual el mundo del que somos solidarios no es un mosaico de objetos o de cuerpos aislables, descomponibles 
y vueltos a conectar por relaciones secundarias con respecto a lo que ellos son en sí mismos. Este mundo está formado por sistemas lentamente estabilizados sobre la base de las interacciones entre sus componentes, ya sean ellos físicos o biológicos. El equilibrio del medio terrestre, condición de la constancia estructural de las realidades familiares, reposa sobre las relaciones circulares que aseguran el mantenimiento de las características singulares propias de esta región del cosmos. Eso quiere decir que el mundo no es un almacén de materiales del que sería posible extraer indefinidamente elementos y al que sería posible devolverle indefinidamente los sub-productos de nuestra producción. La naturaleza en torno nuestro -bajo la forma que le conocemos- aparece como un sorprendente islote neguentrópico en el seno del universo, pero también como el resultado precario de equilibrios fluctuantes.

Esta concepción es bien diferente de aquella que sugiere el dominio técnico de la naturaleza, dominación que tendría por únicos límites los de la potencia disponible para transformar las cosas, es decir, para darles puntualmente la forma que deseamos obtener, olvidándonos o desinteresándonos de los residuos de esas operaciones de transformación por fuera de la obtención del producto. Esta es una mutación de la mirada análoga, pero de sentido inverso, a la que se operó en el siglo XVIII, "del mundo cerrado al universo infinito"11. En torno nuestro, y a pesar de las proezas de nuestras agencias espaciales, reaparece una finitud fundada en la precariedad de los grandes equilibrios.

En 1981, el oficialísimo Programa de las Naciones Unidas para el entorno publicó una introducción excepcional a su reporte anual. Tenía por título "Estrategia mundial para la conservación"; título que hay que meditar. Luego de tres siglos nuestras sociedades se han organizado, estructurado en torno al proyecto de una apropiación generalizada de la naturaleza, es decir, de la transformación de lo que nos rodea. Hemos medido el valor, el precio de las cosas, de la tierra, de las materias primas con su capacidad de ser transformadas por nuestras actividades para integrarse, bajo forma de productos, en los circuitos de intercambios económicos. Imponer que se tenga en cuenta la exigencia de conservación es tomar el contrapié de una organización y de mentalidades sólidamente ancladas en nuestras culturas y generadoras de evidencias. La dificultad de la tarea puede ser simbolizada por otro título: el que le dio a su libro, especie de testamento político, el primero de los ministros franceses del medioambiente, cuando al dejar sus funciones publicó el Ministerio de lo imposible ${ }^{12}$.

Las modificaciones que, a pesar de todo, afectan y deberán afectar nuestras representaciones del mundo y de nuestra inserción en él están ligadas a la forma

\footnotetext{
11 A. Koyré (1957). Del mundo cerrado al universo infinito. Buenos Aires: Siglo XXI, 1979. < http://juliobeltran. wdfiles.com/local--files/cursos\%3Aebooks/Koyre __Del_Mundo-cerrado.pdf >

12 Robert Poujade. Le Ministère de l'impossible. París: Calmann-Lévy, 1975.
} 
que ha adoptado nuestra tecnología, a la vez, en su continuidad con respecto a la herencia precedentemente descrita, y en su especificidad ligada a las mutaciones que atraviesa. Habría que recordar aquí algunos aspectos, sobre todo los tres que hemos evocado.

El primero está en línea recta con esa búsqueda de potencia y más potencia, que está en el corazón del progreso técnico y que conduce al control de las energías a niveles tales que permiten intervenciones a escala de las interacciones fundamentales sobre las que reposan los equilibrios de la biosfera. Pudimos hasta hace poco pensar que había inconmensurabilidad entre las fuerzas de que disponíamos y las de la Naturaleza.

Hoy sabemos que somos capaces de imponer cambios profundos, irreversibles, aunque imprevisibles a las condiciones naturales en las que hemos sido formados.

El segundo, de sentido bien diferente, es no el nacimiento sino la brusca renovación y la expansión de las tecnologías de la información (por oposición a las tecnologías energéticas), tal y como ha sido descrito aquí mismo.

El tercero coincide con la constitución de objetos técnicos a escala de continentes o del planeta, con la formación en redes de grandes circuitos de distribución de la energía y de la información, generadores de formas nuevas de relaciones sociales.

Todo esto modifica muy profundamente las relaciones entre los hombres, y especialmente las relaciones de poder. Todo desarrollo de la potencia sobre las cosas genera inevitablemente relaciones espontáneas de dependencia, por tanto de poder y de conflicto, con todo lo que eso implica de hacerse cargo de esas relaciones y de esos conflictos al nivel de las instituciones políticas.

Grande es la tentación (y sería fácil caer en ella) que empuja a concluir sobre condenas o exhortaciones morales. Pero ante toda utopía naturalista, todo pesimismo desesperado o toda proclama de fe humanista, requerimos repensar lo que somos, a la luz de lo que hemos hecho y de aquello en lo que nos hemos convertido. Es preciso tratar de determinar la manera como existimos, es decir, también cómo coexistimos con todas las otras formas de realidad, y elaborar una antropología a la medida de los desafíos que nos lanza la potencia de nuestros medios de actuar sobre lo que nos rodea.

Para ser a la vez rápido y sugestivo, que se nos permita sustituir los antiguos dualismos por una dualidad de tendencia cuya armonía no está garantizada por ningún orden preestablecido. 
Por toda una cara de nuestro ser, somos vivientes. Participamos en el mundo de la vida, primero, porque hemos salido en tanto que especie recogiendo y transmitiendo una herencia genética lentamente constituida en relación con el devenir general de la biosfera y del entorno terrestre; segundo, en él participamos en la medida en que todos los grandes registros de la necesidad animal y todas las funciones vitales se reencuentran en el telón de fondo de nuestros comportamientos. Aquí participamos, además, porque nos insertamos en los flujos de intercambios de los que dependen los equilibrios naturales, así solo sea a través del juego fisiológico de la respiración.

Pero al mismo tiempo, nada de que somos vivientes como los otros, y nuestra manera de coexistir con las otras formas de realidad traduce la especificidad de las relaciones que mantenemos con la naturaleza, con lo natural, en nosotros y por fuera de nosotros. Nuestras relaciones con nuestros entornos (como por lo demás con aquello que en nosotros es herencia biológica) traducen ante todo un margen de juego, un flotamiento con respecto a las determinaciones naturales, que remite a la desintegración del sistema que forma un individuo o un grupo viviente con su entorno específico <nicho>. El principio mismo de una existencia humana es algo más que una desregulación y una desestructuración de los procesos de integración al medio; es la aparición de facultades nuevas que abre el horizonte de las posibilidades a partir de las cuales la humanidad se diferencia de la animalidad. Bajo este ángulo de la integración en el juego de los equilibrios naturales somos seres del margen, de la marginalidad, en comparación con el conjunto de las otras formas vivientes. Sin duda que se podría dar de todo esto interpretaciones metafísicas divergentes. Pero nosotros solamente constataremos que somos unos seres tales que la herencia de las morfogénesis naturales los condenan a su propio rebasamiento, o a la destrucción ${ }^{13}$.

El ser humano -el ser que existe de manera humana- se caracteriza por la necesidad y la posibilidad de integrar lo que hace de él un ser viviente en formas nuevas, dándole así forma a su sentido más fuerte, ese que evoca su oposición y su complementariedad con la materia ${ }^{14}$. De esta manera los hombres, incluidos los que no eran aún de nuestra especie, han podido y debido producir mediaciones que se interpusieron entre lo natural en ellos (como dato biológico) y la naturaleza en torno a ellos. Esas mediaciones están constituidas por herramientas, signos, normas, instituciones, a través de las cuales han desarrollado sus conexiones con las cosas, el orden de sus representaciones y la regulación

13 Cfr. F. Tinland. La Différence anthropologique. París: Aubier-Montaigne, 1977 <apenas nos enteramos que hace 40 años F. Tinland le había torcido el pescuezo a la sociobiologia... nos encanta ponerlo al lado de quien nos ayudó a pensar este mismo asunto, P. Tort: una lectura de Darwin que mostraba que la humanidad es producto de un efecto de torcedura de pescuezo de nuestra condición biológica, anclada en la fisiología de nuestro cerebro... Paláu>

14 Loados sean Aristóteles... y iiDagognet, morfólogo y materiólogo!! Nota del traductudor. 
de sus relaciones mutuas. Pero las palabras, las herramientas, las reglas, no constituyen unidades aislables, auto-suficientes. Así como las palabras solo tienen sentido en y por una lengua, de la misma manera, las herramientas solo son posibles y eficaces en y por un medio técnico, y por sus pertenencias a una tecnología que constituye sistema.

Es decir, también que las realizaciones simbólicas y técnicas que nacen de nuestros gestos y de nuestras palabras se organizan y se desarrollan en sistemas. Las leyes y procesos que presiden dicha organización y ese desarrollo escapan a la consciencia de los hombres. Pero, al mismo tiempo, esas mediaciones que son las lenguas, las tecnologías, las estructuras de intercambios y de circulación de los bienes en su tendencia a la autonomía auto-organizadora, no constituyen un frente a nuestra disposición.

Ellas no están a la disposición de sus utilizadores como lo estarían simples panoplias de instrumentos que se pueden tomar o que se pueden dejar según las ocasiones.

No hay, por una parte, hombres que piensan, que desean, que actúan según lo que son en virtud de una esencia inmutable, y por otra parte, palabras, herramientas, bienes y circuitos de intercambios.

Hay procesos de estructuración, de producción y de emergencia de las formas estructuradas que conducen a esa realidad completamente singular entre todas aquellas de las que podemos tener experiencia y que es un individuo o un grupo que existe a la manera humana; es decir, presentando para ello las características diferenciales en las que se reconoce la humanidad. Existir de manera humana es pues reportarse de manera singular al mundo, a los otros y a sí mismo, apoyándose para ello en las mediaciones simbólicas y técnicas heredadas por vía tradicional, pero siempre retomadas, reapropiadas y más o menos transformadas a través de las prácticas actuales.

Entre estas dos caras -herencia de la vida, herencia de lo que nacen los gestos y las palabras de los hombres al mismo tiempo que reestructuran sus relaciones con toda realidad en ellos o por fuera de ellos- no hay necesariamente acuerdo. Habría que meditar sobre el lazo de esta misma dualidad con la condición de que es la nuestra al término de tres millones de años de un desarrollo cuya herencia la hace fructificar nuestra tecnología.

Es posible que nuestra existencia en tanto que seres humanos (nuestra humanidad) esté fundada en una contradicción insuperable cuya oposición entre conservación y transformación sería un eco lejano y debilitado. Se podría entonces concluir de ello que pertenece a nuestra esencia ser llamados a la auto-destrucción, y que lo que tenemos como propio (o que somos propiamen- 
te) empuja así a la erosión de las condiciones que constituyen el basamento natural de una vida que se desarrolla al margen de la vida. Esta conclusión, sin embargo, no es necesaria.

Todo lo que hemos dicho tiende a mostrar que ya no tenemos el dominio espontáneo de nuestras producciones como tampoco de los procesos naturales ellos mismos. Pero "no más" no significa "menos". Lo que aparece con la consciencia, o más bien como consciencia, es una posibilidad de distanciamiento que reposa en la información y el conocimiento, y reintroduce, en otro plano distinto al del juego espontáneo de los procesos de composición y de descomposición que trabajan tanto en la naturaleza como en las sociedad, un horizonte de elección, de bifurcaciones posibles, de encrucijadas al borde de las cuales el devenir hesita.

Lo que designamos como crisis es seguramente el fruto de un conjunto complejo de mutaciones. Está permitido pensar que estas se inscriben por una parte directamente en una historia muy larga y opaca a la conciencia inmediata como a la mirada que estamos habituados a echar sobre nuestro pasado; y por otra parte, introducen a una condición radicalmente nueva. Del primer punto de vista importa reencontrar la dinámica propia para el acrecentamiento de nuestra potencia sobre las cosas y de estimar bien lo que puede haber de espontáneamente autónomo, emancipado con respecto a las intenciones que hacen actuar a los hombres, el devenir de los sistemas mediadores del que sacamos nuestro poder. Desde el segundo punto de vista, importa tomar la medida de los desafíos con los cuales estamos confrontados sin disponer, a partir de nuestra historia antigua o reciente, de los esquemas de pensamiento y de las estructuras institucionales capaces de responder acá.

El esfuerzo teórico es aquí de primera necesidad, y debe ligar a la preocupación por volver a poner las dificultades contemporáneas sobre el fondo de lo que las hace posibles (en el límite: desde comienzos de la hominización) una apreciación exacta de lo que hace que nuestro mundo no sea ya ese del siglo XIX, ni siquiera el de hace veinte años.

Pero si esta reevaluación y esta atención nueva a nuestra propia realidad son relativamente fáciles de teorizar, no ocurre lo mismo con el sujetamiento del desarrollo técnico a las conclusiones que es posible sacar de estos análisis. La realidad misma es sorda a los mandatos salidos de nuestros discursos. La mediación técnica, tal como la hemos descrito en la autonomía de su organización y de su dinamismo, hace parte de esta realidad, resistente al querer, y al comienzo opaca a la mirada. Ella conduce espontáneamente a la explotación de las posibilidades que abre el desarrollo de los medios de acción sobre las cosas y a la reconstitución de horizonte de los posibles realizables. Ella conduce a la 
movilización de las disponibilidades económicas y de los esfuerzos humanos con miras a una más grande eficacia en la apropiación del dato natural.

Sin duda, podemos descubrir grietas cuya agravación pondría en peligro la armoniosa integración de la dinámica de la apropiación eficaz en el conjunto socio-cultural que se ha estructurado desde los comienzos de los tiempos modernos en Europa occidental. Las alteraciones suscitadas por la presión técnica sobre las condiciones ecológicas y las distorsiones debidas al diferencial de desarrollo según las regiones del globo han hecho nacer inquietudes, por no llamarlas angustias que han conmovido las ideologías del progreso.

Pero si estas grietas fisuran la cohesión de los proyectos colectivos cristalizados en torno a la dominación y posesión de la naturaleza, ellas no conducen a olvidar que el aumento de la potencia de los medios creados por el desarrollo tecnológico se remonta mucho más allá de la sinergia socio-cultural propia de la civilización occidental. Es necesario recordar lo que ya decíamos de su enraizamiento en el devenir de las formas vivientes y de su emancipación con respecto al mundo de la vida. Estamos hablando acá de algo esencial a la manera como los seres humanos son confrontados con el mundo, esencial a su manera de ser, incluso si casi siempre y casi por todas partes los modos colectivos de existencia y su orden simbólico han mantenido esta dinámica auto-organizacional al nivel de las actividades subordinadas, mientras que llegó a ser -y con razónreconocida su necesidad.

Venida de bien lejos, profundamente ligada a lo que somos, igualmente bien acorde con las exigencias del intercambio generalizado y con una economía que solo puede buscar equilibrios en una carrera técnica en búsqueda de eficacia (a través de las redes de interacciones que solidarizan nuestros medios técnicos y que le dan al sistema técnico su autonomía dinámica) desborda con mucho la conciencia que de ella tenemos, estructura nuestras estrategias más de lo que refleja nuestra voluntad.

Por esto debemos temer que, incluso ante la cuasi-evidencia de los peligros ecológicos y de los desórdenes engendrados por las distorsiones en el desarrollo tecno-económico, los hombres no sigan siendo los instrumentos de una alteración de sus condiciones de vida -y esto a través de la continuación de este esfuerzo que le ha dado a los resultados de la tecnicidad humana una potencia que nunca ha sido puramente instrumental-, una potencia que nunca se ha reducido al estatus de instrumento a la simple disposición de sus utilizadores.

$\mathrm{Y}$, sin embargo, esto no debe conducirnos a un pesimismo, que con gusto se vuelve apocalíptico, sino que esto implica un esfuerzo para dotarse de los medios para regular el curso de nuestras propias actividades. Estas pertenecen a conjuntos en el seno de los cuales ellas toman su sentido sin que nosotros 
seamos inmediatamente conscientes de ello. Lo que nace de nuestras prácticas no es transparente a nuestras inteligencias como tampoco lo es lo que engendran los procesos naturales. Y así como solo podemos orientar estos últimos en la medida en que lleguemos a conquistar su conocimiento, asimismo, requerimos comenzar por analizar lo que está en juego tras las formas presentes de mediaciones técnicas.

También necesitamos saber lo que queremos, una vez considerados todos los factores, es decir, teniendo en cuenta tanto la comunidad de este mundo, que nos hace necesariamente solidarios los unos de los otros, como la oposición de los intereses que nos dividen, sobre la base especialmente de la irreductibilidad de las posiciones de los unos y de los otros con respecto a las formas y ritmos del desarrollo. Y cuando se sabe lo que se quiere, o más bien cuando es posible ponerse de acuerdo sobre lo que está permitido querer, es necesario dotarse de los medios para realizar los objetivos así definidos, crear las condiciones del paso de los votos piadosos a una acción sobre la realidad de los procesos cuyo curso es deseable regular.

Dejado al garete, el proceso que lleva a la búsqueda de una eficacia siempre más grande en la acción sobre la realidad natural conduce sin ninguna duda a desequilibrios crecientes. Pero frente a esta amenaza, conviene sin duda que por medio de una práctica reflexionada y voluntaria, nos demos los medios de orientar y de regular el curso de un devenir que -como el de las estructuras disipativas- se nutre de sus propias condiciones hasta destruir su propia base.

En resumen: de la toma de consciencia colectiva de las modalidades y de los efectos del desarrollo tal como él mismo se mantiene, abriendo para sí mismo la vía de los nuevos posibles y movilizando los recursos y energías disponibles... al control de las orientaciones y de los efectos de esta tendencia a la auto-realización... se requieren intermediarios. Es menester que el querer consciente mismo consiga los medios de su ambición. Esos medios solo pueden ser institucionales, y no pueden ser operatorios sino apoyándose sobre redes de información y de formación en la dimensión de los problemas por resolver. Habría que poner a funcionar organismos colectivos de gestión de los recursos naturales y de apropiación de los sistemas tecnológicos, que estén en capacidad de controlar los desequilibrios que amenazan con desestabilizar el mundo natural, y las distorsiones que ahondan la brecha entre áreas geopolíticas en función de las formas y ritmos de desarrollo.

La unidad y la unicidad de un mundo que es el patrimonio común de la humanidad exigirían esta co-gestión cuya urgencia se medirá sin por tanto pensar en su realización en un cercano porvenir. Pero ¿será menos verdadero hoy que en el siglo XVII lo de que no es necesario esperar para comenzar? 